\title{
Potential Effects of the Loss of Native Grasses on Grassland Invertebrate Diversity in Southeastern Australia
}

\author{
Roger Edgcumbe Clay \\ School of Natural \& Built Environments and Barbara Hardy Institute, University of South Australia, Mawson Lakes, SA 5095, Australia \\ Correspondence should be addressed to Roger Edgcumbe Clay; roger.clay4@bigpond.com
}

Received 27 September 2014; Revised 11 November 2014; Accepted 12 November 2014; Published 1 December 2014

Academic Editor: Béla Tóthmérész

Copyright ( 2014 Roger Edgcumbe Clay. This is an open access article distributed under the Creative Commons Attribution License, which permits unrestricted use, distribution, and reproduction in any medium, provided the original work is properly cited.

Reduction in area of the southeastern temperate grasslands of Australia since European settlement has been accompanied by degradation of remaining remnants by various factors, including the replacement of native plant species by introduced ones. There are suggestions that these replacements have had deleterious effects on the invertebrate grassland community, but there is little evidence to support these suggestions. In the eastern Adelaide Hills of South Australia, four grassland invertebrate sampling areas, in close proximity, were chosen to be as similar as possible except for the visible amount of native grass they contained. Sample areas were surveyed in four periods (summer, winter, spring, and a repeat summer) using pitfall traps and sweep-netting. A vegetation cover survey was conducted in spring. Morphospecies richness and Fisher's alpha were compared and showed significant differences between sample areas, mainly in the summer periods. Regression analyses between morphospecies richness and various features of the groundcover/surface showed a strong positive and logical association between native grass cover and morphospecies richness. Two other associations with richness were less strong and lacked a logical explanation. If the suggested direct effect of native grass cover on invertebrate diversity is true, it has serious implications for the conservation of invertebrate biodiversity.

\section{Introduction}

The southeastern temperate grasslands of Australia have been greatly affected by European settlement and agriculture. There has been a large reduction in total area of these grasslands and resulting remnants are usually small and isolated from one another [1]. Almost invariably the remnants have been invaded by introduced plant species (e.g., [2, 3]). Grazing pressure from domestic stock and competition from invasive exotic plants, amongst other factors, have resulted in the reduction of native perennial grasses and their replacement by introduced annual grasses. There also has been an associated loss of native forbs and their replacement by broadleaf exotics (usually annuals).

Yen et al. [4] have shown temperate grassland sites across western Victoria, Australia, to have a diverse invertebrate fauna with high species turnover between sites. The contributions of the different orders of invertebrates to total abundance were also highly variable between sites. This dynamism is reinforced by seasonal changes in the invertebrate community and year-to-year turnover in a temperate grassland in South Australia [5]. Examinations of the invertebrate families occurring in grasslands in Victoria [4] and South Australia [5] show that all trophic levels are well represented in the assemblage and suggest an important role for the invertebrate community in grassland ecosystems.

Our knowledge of the invertebrate communities of southeastern temperate grasslands is improving; however there has been little study of the effects of the exotic plant invasion, described above, on these invertebrate communities. Generally, knowledge of the effects of exotic plants on insect communities is limited [6, page 115]. A comprehensive assessment of arthropod assemblages in 46 grassland sites in The Netherlands concluded that plant species composition was the "most effective predictor" of the associated arthropod assemblage compared to four other potential predictors [7]. This predictive value of plant composition adds support to the assumption that loss of native plants has led to loss of invertebrate species [8]. However, Samways [6, page 78] highlights the difficulty of distinguishing between 
the effects of different types of disturbance, especially as they are likely to have synergistic interactions. For example, Faithfull [9] consistently found lower invertebrate species richness in kangaroo grassland (Themeda australis) invaded by Chilean needlegrass (Nassella neesiana) compared to uninvaded areas. However, this reduction could not be definitively attributed to the invasive plant species because of associated disturbances.

For specific insects/insect groups, the effects of exotic plant invasions are variable. Grasshoppers in pampas grassland were not adversely affected by such intrusions [10], and no consistent relationship was found between ant species richness and degree of replacement of native grasses [8]. However, leafhoppers in German grasslands were adversely affected [11]. Invasion of prairie grasslands in the USA Midwest by exotic grasses is claimed to be detrimental to the survival of populations of the Dakota skipper (Hesperia dacotae L.) [12]. However, the invasive Chilean needlegrass (Nassella neesiana) may provide food for the larvae of the golden sun-moth (Synemon plana Walker) in grasslands of southeastern Australia [13].

Given the possibility that invasive exotic plants are adversely affecting invertebrate conservation and the lack of definitive evidence, this study considered the following questions.

(i) Do sampling areas that have been deliberately chosen to have differences in relative abundance of introduced and native grasses display differences in invertebrate diversity?

(ii) If there are differences, are they consistent across seasons?

(iii) If there are differences between sampling areas, can they be attributed to different degrees of replacement of native grasses?

\section{Methods}

2.1. Survey Site. The survey was conducted in the eastern Adelaide Hills in the Bremer River valley (Hundred of Kanmantoo; $\left.\mathrm{S} 35^{\circ} 00^{\prime} 19.4^{\prime \prime}, \mathrm{E} 139^{\circ} 01^{\prime} 55.2^{\prime \prime}\right)$. The survey site slopes downward towards the river in an ESE direction. Soils, predominantly clay-loams, are shallow and rock outcrops occur. The site's elevation is $190-200 \mathrm{~m}$. The area has a Mediterranean-type climate with warm to hot and dry summers and cooler winters when most of the rain falls. The long-term annual average rainfall is $468 \mathrm{~mm}$ at the nearest recording station $(7.5 \mathrm{~km}$ away) and average daily maximum and minimum temperatures are $23.3^{\circ} \mathrm{C}$ and $9.1^{\circ} \mathrm{C}$, respectively [14].

The site lies within the distribution of Community Type S4 (midnorth tussock grassland) [3] and is also within the distributions of Peppermint Box (Eucalyptus odorata) Grassy Woodland and Iron-grass Natural Temperate Grassland communities [15]. The community at the survey site is a disclimax community (due to deliberate removal of trees) that has elements of all three of the communities mentioned above [5]. It is highly unlikely that the site has ever been cultivated for cropping, but it has probably been grazed by domestic stock for more than 100 years. At the time this study commenced, the site had not been grazed by domestic stock for seven years and not burnt for at least ten years.

2.2. Survey Period. The survey occurred between February 2007 and late February 2008, with four sampling periods: February, July, and September/October 2007 provided summer, winter, and spring sampling, respectively; February 2008 provided a repeat summer sampling.

Coincidentally, this was a period of low rainfall; the three years, 2006-8, were 20-30\% below long-term average. During the sampling periods, only $12.6 \mathrm{~mm}$ of rain was recorded (with $7 \mathrm{~mm}$ being the largest single fall). The average daily maximum temperature during summer samplings was $28^{\circ} \mathrm{C}$ and average daily minimum $14^{\circ} \mathrm{C}$. Similar recordings for winter were $14^{\circ} \mathrm{C}$ and $6^{\circ} \mathrm{C}$ and for spring $20^{\circ} \mathrm{C}$ and $10^{\circ} \mathrm{C}$.

2.3. Sampling Areas. The work of Yen et al. [4] clearly showed the spatial variability present in grassland insect communities. Since the focus of this study was potential differences associated with the presence/absence of native grasses, sampling areas were confined to a small area to reduce the influence of confounding factors, such as the spatial variability mentioned above, and differences in slope, aspect, soil type, past management, and so forth. Four sampling areas, each a $15 \times 20 \mathrm{~m}$ rectangle, were chosen within an area of 1 ha (approximately). This area had heterogeneous groundcover, particularly with respect to native grasses, with a range from no obvious native grass to quite obvious presence. Because of this heterogeneity, replication was considered impossible and, instead, it was decided to quantify differences in ground cover/surface between sampling areas by a detailed survey (see below). Two sampling areas were chosen to contain obvious native perennial grass and two had no obvious native grass. They were designated EP, EA, $\mathrm{WP}$, and WA (E/W for east and west locations, P native grass, and A no native grass). East/west designations do not imply different aspects or large separations. All sampling areas had ESE aspects (approximately) and their slopes ranged from 7 to $9^{\circ}$. Because the research emphasis was on groundcover invertebrates, captures were minimised from other strata by choosing sampling areas without trees and shrubs in them or in the immediate vicinity.

2.4. Vegetation Survey. A groundcover vegetation survey was conducted on 1-2 November 2007 in each sampling area. A point quadrat frame, $0.5 \mathrm{~m}$ long and with ten points (needles), was centred on $2 \mathrm{~m}$ intervals along transects. There were three transects per sampling area parallel to the longer side of the rectangle and placed to either side and between the two pitfall transects (see below). For each transect there were ten frames and therefore 30 per site, equivalent to 300 data points. All plants touched by a point were identified, if possible, and recorded. In addition, the nature of the ground surface reached by each point was recorded. Differences between sites, in the number of hits per frame on plants (total plant cover), were tested by ANOVA. Correlation coefficients 
between some of the different types of cover/surface were also determined.

2.5. Sampling Invertebrates. Surface-active invertebrates were sampled with micropitfall (mpf) traps of diameter $43 \mathrm{~mm}$. At least five days before the first sampling began, PVC sleeves with lids were inserted into the soil. The sleeves enabled the actual traps to be placed and removed with minimal soil disturbance for all sampling periods and thus minimised digging-in effects [16]. Each trap was partially filled with a 2:1 mixture of propylene glycol and water. A drop of soap solution was added to reduce surface tension. Propylene glycol was preferred to ethylene glycol (antifreeze) because the latter is apparently both attractive and toxic to vertebrates [17]. For each sampling period, traps were in place for seven consecutive days and nights. Each site had $14 \mathrm{mpfs}$ in two rows of seven mpfs. These rows were parallel to the long axis of the rectangle with $3 \mathrm{~m}$ between mpfs in the row and $5 \mathrm{~m}$ between the rows.

Because of the lack of previous surveys in South Australian grasslands, simultaneous sampling of a wide range of invertebrates was considered appropriate. It was assumed that different diameters of mpfs would create positive and negative biases towards particular invertebrate groups with no specific diameter optimal. The diameter $(43 \mathrm{~mm})$ chosen tends to be in the midrange of possible sizes and has been found to be efficient for sampling ants [18].

Invertebrates located within the grass and herb foliage were sampled by sweep-netting through the foliage (rather than above it). At each sampling area and sampling period, sweeping was done three times during the week when the micropitfalls were in place. These samplings were made as comparable and repeatable as possible by following a similar path, at a consistent pace, through each sample area. A pooter was used to remove invertebrates from the net on-site, and they were immediately placed into vials containing $70 \%$ ethyl alcohol. The consistent application of sweep-netting across sampling periods and areas enabled valid comparisons of presence/absence data. However, valid comparisons of relative abundances cannot be made because grass seeds stuck in the net made it impossible to collect all individuals of some small species. Consequently, sweep-netting abundances are only indicative.

2.6. Processing Invertebrates. In the laboratory, all invertebrates were removed from pitfalls and identified to major taxonomic groups (usually to order). Within these groups, individuals were judged to be similar/different on the basis of external morphology and thus separated into morphospecies. The use of morphospecies has been justified in studies of this type [19]. Voucher specimens of each morphospecies were preserved. The number of individuals of each morphospecies in each pitfall was also recorded. Individuals from sweepnetting samples were also identified to order and placed in morphospecies. Unfortunately, limited time and expertise made it impossible to process the overwhelming number of springtails (Collembola) and they were excluded from subsequent analyses. Known introduced species, 13 in all and
$<3 \%$ of total morphospecies, were also excluded. A variety of keys, both printed and interactive (DVDs), were used to place morphospecies in families. Wherever possible, these designations were verified by experts. Additional details of the processing can be found in Clay and Allen [5].

\subsection{Data Analysis}

2.7.1. Outliers. Although most morphospecies were represented by less than ten individuals [5], there were a few abundant species in particular sampling areas and periods. Potentially, these are statistical outliers that can severely bias indices and invalidate statistical tests. Abundance data were checked for each sampling area and sampling period or combinations. Any residual greater than 4 times the standard deviation [20, page 83] for that period and area indicated the presence of an outlier and the species was removed from the calculation of Fisher's $\alpha$ but retained in richness data. For all sampling areas and periods, only four morphospecies were excluded at one time or another. Their residuals ranged from 4.7 to 35 times larger than the respective standard deviation.

2.7.2. Diversity Measures. Species richness and Fisher's alpha $(\alpha)$ were used to compare the invertebrate diversity of sampling areas, following the advice of Magurran [21]. The focus of this study is the potential conservation value of native grasses for the invertebrate fauna; therefore rare species are important. Their influence is retained by the use of presence/absence data but is diminished by diversity measures which include abundance data. In addition, species richness is biologically meaningful and commonly used [21]. Of diversity measures that include abundance, Simpson's index and Fisher's $\alpha$ are the most commonly used. Both are relatively unaffected by sample size; however the former is readily biased by abundant species [21]. Tests on this study's data confirmed the greater bias of Simpson's index. For example, removal of only one abundant ant species from sampling area EP (February 2007) data changed Simpson's index from 2.0 to 13.4 and $\alpha$ from 14.6 to 20.9. Clearly, both indices are sensitive to the presence of abundant species, but the effect on the former is much greater. Fisher's $\alpha$ also provides the advantage of direct calculation of standard errors.

Differences between sampling areas in morphospecies richness (totals for both capture methods) were tested by 2 way ANOVA. Each cell in the data table had a single value for total richness with cells classified according to both sample area and sampling period. Three combinations of sampling periods were tested, namely, (1) all four sampling periods, (2) the three periods of 2007, and (3) the two February (summer) periods.

Fisher's $\alpha$ indices and their standard errors were calculated, from pitfall captures only, for each sampling area and sampling period and compared by " $t$-tests."

2.7.3. Morphospecies Richness and Groundcover/Surface Associations. Possible associations were explored by principal component analyses (PCA). Strong associations identified by 
PCA were then examined by pairwise regression analyses with richness the dependent variable. (The small number of sampling areas made the use of multiple regression invalid.) Separate analyses were done for each sampling period and two combinations of periods, namely, the three periods in 2007 and the two summer periods. In each case pitfall and sweep-netting captures were analysed separately and in combination. ANOVA were used to determine significant regressions.

\section{Results}

Over the four sampling periods, 13,729 individuals were captured by both methods, representing 544 different morphospecies from at least 28 orders and 143 families. These data do not include known introduced species or Collembola ( $>20,000$ springtails were captured). More detail is given in Clay and Allen [5].

3.1. Comparisons of Sampling Areas: Pitfall and Sweep-Netting Morphospecies Richness. Table 1 and Figure 1 provide morphospecies richness for each sampling area and period and two combinations of periods. With only one exception, October 2007, the ranking of sampling areas in each period, or combination, is $\mathrm{WP}>\mathrm{EP}>\mathrm{WA} \geq \mathrm{EA}$. The ranges of richness values are also given in Table 1 and indicate that differences were greatest in summer and least in spring.

Table 2 gives average richness values for the three different combinations of sampling periods, namely, all four periods, the three periods of 2007, and the two summer periods. With one minor exception, the numerical order of sampling areas conformed to the rank order (above). Statistical tests for both methods of capture (Table 2(a)) show that two of the combinations had significant differences between sampling areas. For pitfall captures only, Table 2(b) shows that a difference between sampling areas occurred in the combination of the two summer periods, whereas, for sweep-netting captures only, differences occurred for two combinations (Table 2(c)). Any significant differences between average richness values always conformed to the rank order: WP $>$ EP $>$ WA $\geq$ EA.

Many morphospecies were only captured in one sampling area over all survey periods. If species are randomly distributed across the survey area, there should be an approximately equal number of these "single occurrence" species in each sampling area. Over the four survey periods there were 289 "single occurrences" as follows: EP (84), EA (50), WP (83), and WA (72). Chi-square (testing for equal numbers) was significant, $10.36(P<0.02)$, thus suggesting a nonrandom distribution favouring the $\mathrm{P}$ sampling areas.

3.2. Comparisons of Sampling Areas: Fisher's Alpha. Alpha indices (Table 3(a)) were based only on pitfall data where, in contrast to sweep-netting data, reliable abundances were available. Rankings within each sampling period, or combination, show close agreement with the rankings for species richness. With the exception of October 2007, area EP or area WP has the largest alpha and usually both are larger

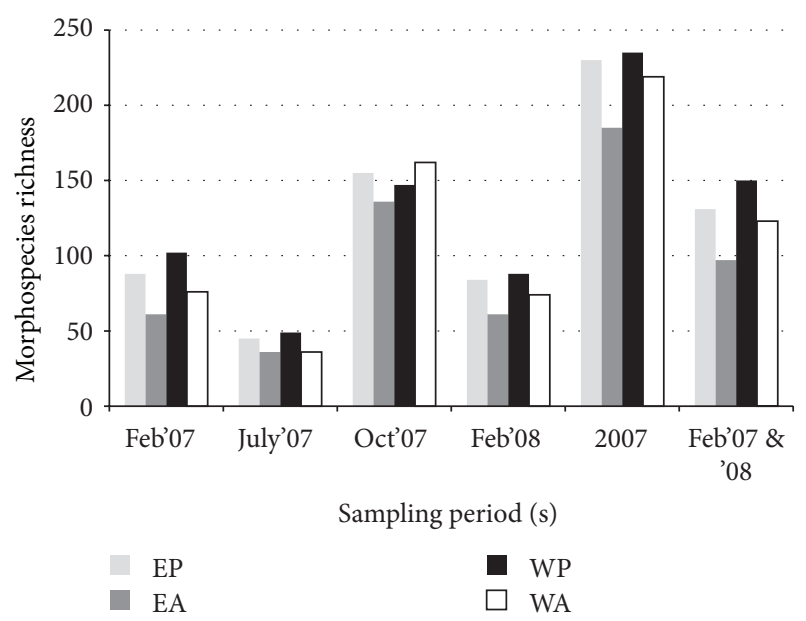

FIGURE 1: Morphospecies richness (both capture methods combined) for each sampling area in each sampling period or combination of periods; EP, EA, WP, and WA are the designations of the four sampling areas.

TABLE 1: Morphospecies richness (both capture methods) for each sampling area and period and two combinations of periods ${ }^{\mathrm{a}}$.

\begin{tabular}{lcccccc}
\hline \multirow{2}{*}{ Sampling period(s) } & \multicolumn{3}{c}{ Sampling area } & \multicolumn{2}{c}{ Range } \\
& EP & EA & WP & WA & Number & $\%^{*}$ \\
\hline February 2007 & 88 & 61 & 102 & 76 & 41 & 67 \\
July 2007 & 45 & 36 & 49 & 36 & 13 & 36 \\
October 2007 & 155 & 136 & 147 & 162 & 26 & 19 \\
February 2008 & 84 & 61 & 88 & 74 & 27 & 44 \\
2007 (3 periods) & 230 & 185 & 235 & 219 & 50 & 27 \\
February 2007 and 2008 & 131 & 97 & 150 & 123 & 53 & 55 \\
\hline
\end{tabular}

${ }^{a}$ Captures are included from both methods, but if a species was captured by both methods in the same sampling area and period it was only counted once. Similarly for combinations of periods, if the same species was captured in the same sampling area in different periods, it was only counted once.

* Percentage difference between the smallest and largest richness values in each sampling period or combination of periods.

than those of areas EA or WA. Table 3(b) indicates which differences are statistically significant (by $t$-test). In any comparison of a $\mathrm{P}$ area with an $\mathrm{A}$ area that is significant, it is always to the advantage of the $\mathrm{P}$ area. Clearly, this advantage is most pronounced in the summer surveys, including the combination of the two summers. As was the case with species richness, EA is usually the least diverse.

3.3. Comparisons of Sampling Areas: Abundance. Table 4 gives pitfall abundances and totals for each sampling area and period. More than 11,000 invertebrates were captured in pitfalls, excluding Collembola and known introduced species. The last row of Table 4 shows much higher abundance for EP than other areas. However, this is mostly due to captures of the ant Anonychomyrma sp.2 (4200 individuals in EP). Removal of this species, and three other statistical outliers, from the data of various sampling periods, gives the values shown in the remainder of the table. These are more uniform and a 2-way ANOVA over the four sampling periods showed 
TABLE 2: Average morphospecies richness ${ }^{\mathrm{a}}$ for each sampling area for three combinations of sampling periods, $F$ values, and listing of averages that were significantly different. (a) Combined captures of both methods ${ }^{\mathrm{b}}$. (b) Captures from pitfalls only. (c) Captures from sweep-netting only.

(a) Combined captures of both methods

\begin{tabular}{|c|c|c|c|c|c|}
\hline Sampling periods & EP & EA & $\mathrm{WP}$ & WA & $F$ value and probability ${ }^{c}$ \\
\hline All four periods & 93.0 & 73.5 & 96.5 & 87.0 & $5.9<0.02$ \\
\hline Three periods in 2007 & 96.0 & 77.7 & 99.3 & 91.3 & $2.7>0.10$ \\
\hline \multicolumn{6}{|c|}{ Differences ${ }^{\mathrm{d}}$ EP \& WP $>$ EA (0.01); WA $>$ EA $(0.05)$} \\
\hline Both summer periods & 86.0 & 61.0 & 95.0 & 75.0 & $22.2<0.015$ \\
\hline \multicolumn{6}{|c|}{ Differences $^{\mathrm{d}}$ WP $>$ EA (0.01); WP > WA (0.05); EP > EA (0.05) } \\
\hline
\end{tabular}

(b) Captures from pitfalls only

\begin{tabular}{llllll}
\hline Sampling periods & EP & EA & WP & WA & $F$ value and probability $^{\mathrm{c}}$ \\
\hline All four periods & 67.5 & 51.5 & 63.5 & 60.0 & $2.5>0.10$ \\
\hline Three periods in 2007 & 69.7 & 53.0 & 63.3 & 61.7 & $1.3>0.35$ \\
\hline Both summer periods & 66.5 & $\begin{array}{c}45.5 \\
\text { Differences }\end{array}{ }^{\mathrm{d}}$ EP \& WP $>$ EA $(0.05)$ & 55.5 & $9.5<0.05$ \\
\hline
\end{tabular}

(c) Captures from sweep-netting only

\begin{tabular}{|c|c|c|c|c|c|}
\hline Sampling periods & $\mathrm{EP}$ & EA & WP & WA & $F$ value and probability ${ }^{\mathrm{c}}$ \\
\hline All four periods & 30.5 & 25.3 & 37.0 & 29.3 & $15.9<0.001$ \\
\hline \multicolumn{6}{|c|}{ Differences ${ }^{\mathrm{d}}$ WP $>$ EA \& WA (0.01); EP \& WA > EA (0.05) } \\
\hline Three periods in 2007 & 32.3 & 28.3 & 40.3 & 32.7 & $13.2<0.01$ \\
\hline \multicolumn{6}{|c|}{ Differences ${ }^{\mathrm{d}}$ WP $>$ EP, EA \& WA (0.01) } \\
\hline Both summer periods & 21.0 & 17.0 & 27.0 & 21.0 & $2.5>0.20$ \\
\hline
\end{tabular}

${ }^{a}$ Richness values are averages over the specified periods. Known introduced species have been excluded.

${ }^{b}$ If a species was captured by both methods in the same sampling area and period, it was only counted once.

${ }^{c} F$ values and probabilities associated with "sampling areas mean square."

${ }^{\mathrm{d}}$ Determined by LSD (least significant difference) with the probabilities shown.

TABLE 3: (a) Fisher's alpha indices of diversity for each sampling area in each sampling period or combination of periods. (b) Results of Student's $t$-tests indicating where significant differences occurred and, if so, which area had the larger alpha.

(a)

\begin{tabular}{|c|c|c|c|c|}
\hline \multirow{2}{*}{ Sampling period(s) } & \multicolumn{4}{|c|}{ Sampling area } \\
\hline & $\mathrm{EP}$ & EA & WP & WA \\
\hline February 2007 & 20.9 & 12.1 & 28.6 & 16.7 \\
\hline July 2007 & 12.7 & 9.7 & 11.6 & 7.7 \\
\hline October 2007 & 41.0 & 33.6 & 36.2 & 45.4 \\
\hline February 2008 & 20.4 & 16.0 & 22.7 & 17.9 \\
\hline 2007 (3 periods) & 52.6 & 38.3 & 44.4 & 48.0 \\
\hline February 2007 and 2008 & 28.2 & 18.5 & 32.6 & 26.4 \\
\hline
\end{tabular}

(b)

Sampling period(s)

Paired comparisons of sampling areas

\begin{tabular}{ccccccc} 
& EP versus EA & EP versus WP & EP versus WA & EA versus WP & EA versus WA & WP versus WA \\
\hline February 2007 & $\mathrm{EP}^{* * *}$ & $\mathrm{WP}^{*}$ & & $\mathrm{WP}^{* * *}$ & $\mathrm{WA}^{*}$ & $\mathrm{WP}^{* * *}$
\end{tabular}

July 2007

October 2007

February 2008

2007 (3 periods)

February 2007 and 2008

$\mathrm{EP}^{*}$
$\mathrm{EP}^{* * *}$
$\mathrm{EP}^{* * *}$

$\begin{array}{cc}\mathrm{WP}^{*} & \mathrm{WA}^{*} \\ \mathrm{WP}^{* * *} & \mathrm{WA}^{* *} \\ \mathrm{WA}^{* * *}\end{array}$

$\mathrm{WA}^{*}$

a, “*”, “**”, “***” A significant difference at the $0.05,0.01$, and 0.001 probability level, respectively. 
TABLE 4: Pitfall abundances and totals ${ }^{\mathrm{a}}$ for each sampling area and period.

\begin{tabular}{lccccc}
\hline Sampling period & EP & EA & WP & WA & Total \\
\hline February 2007 & 604 & 532 & 430 & 496 & 2062 \\
July 2007 & 79 & 67 & 75 & 54 & 275 \\
October 2007 & 644 & 629 & 471 & 475 & 2219 \\
February 2008 & 444 & 338 & 374 & 395 & 1551 \\
Total excluding outliers & 1771 & 1566 & 1350 & 1420 & 6107 \\
Total including outliers & 6058 & 1701 & 1995 & 1706 & 11460 \\
\hline
\end{tabular}

${ }^{a}$ Excluding Collembola and known introduced species.

no significant differences between average abundances of areas $(F=3.4, P>0.05)$.

3.4. Groundcover Survey. The survey was only done in spring and found that total vegetation cover differed significantly between sampling areas $\left(F_{3,116}=23.0 ; P<0.01\right)$ with $\mathrm{EP}$ having the least cover (average 7.3 hits per 10-point frame), followed by WP (13.9 hits), EA (14.2 hits), and WA (21.5 hits). Least significant difference $(P<0.01)$ showed EP to have significantly less cover than the other three sites, whereas WA had significantly greater cover than the other three.

Floristic composition also differed (Figure 2). The relative percentage cover attributable to grasses ranged from $64 \%$ in EP (equivalent to an average 4.6 hits per frame) to $90 \%$ in EA (equivalent to 13.9 hits). Cover of introduced grasses was the largest component of total cover in all sampling areas. Given that two areas were deliberately chosen to contain noticeable native grasses, relative cover attributable to them differed considerably, $16 \%$ and $22 \%$ for WP and EP, respectively, but only $3 \%$ and $<1 \%$ for WA and EA, respectively. However, absolute covers of native grass (average number of hits per frame) were 2.2, 1.6, 0.7, and 0.1 for WP, EP, WA, and EA, respectively. Most native grasses had little growth, presumably because of well-below average rainfall in 2006 and 2007. Austrostipa species were the main component with Austrodanthonia species and Aristida behriana also present. Avena spp. (wild oats) were the dominant, introduced annual grasses with Bromus spp. being also important. Figure 2 also shows that annual clovers (Trifolium spp.) were a noticeable component of cover in WP, less so in EP and WA, and only minor in EA.

The soil surface was usually covered by plant litter $(73$ to $88 \%$ cover) but in WP it only provided $50 \%$ cover with microphytic crust contributing $37 \%$ cover. At other sites microphytic crust contributed $\leq 10 \%$ cover. Bare soil or rock constituted $13 \%$ of the surface in EP and WA, $6 \%$ in WP, but $<2 \%$ in EA. Live plant material covering the surface was uncommon: ranging from $5 \%$ in WP to $0 \%$ in EA.

3.5. Association of Morphospecies Richness with Groundcover/ Surface Data. Preliminary and exploratory principal components analyses (PCA) revealed that invertebrate richness and covers (average number of hits per frame) of native grass and clover had strong influences, in the same direction, on the first principal component (PC), whereas litter cover had

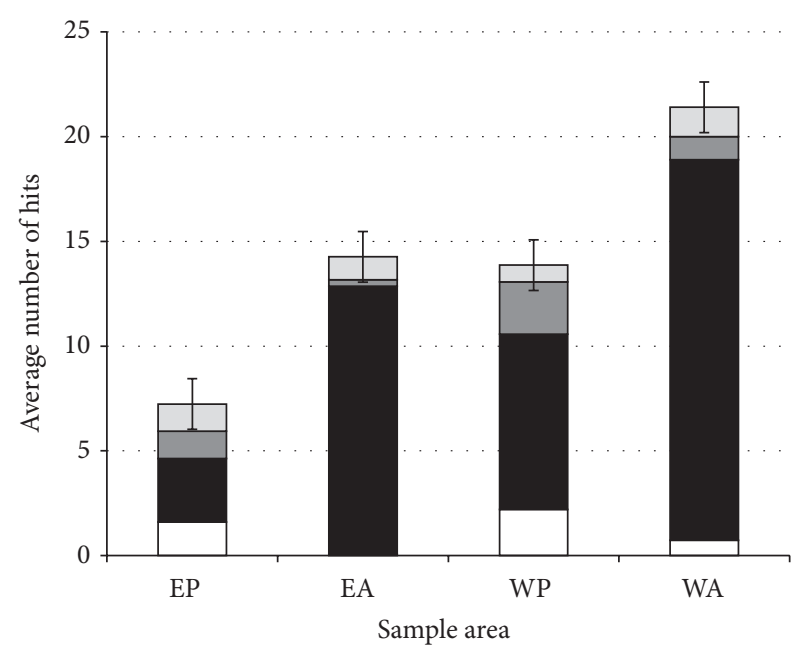

$\square$ Other broadleaf species $\quad \square$ Introduced annual grass
$\square$ Introduced clover species $\quad \square$ Native perennial grass

FIGURE 2: Vegetative cover: average number of hits per point quadrat frame on the four categories of groundcover vegetation for each sampling area. The error bars indicate the standard error of the average total number of hits per frame for all sample areas.

a similarly strong but opposite effect. The cover of introduced grasses also had an opposite, but lesser, effect. Examples of these analyses are shown in Figure 3. This pattern of relationships was consistently displayed over all sampling periods and the two combinations of periods, although richness made a smaller contribution in the October 2007 sampling period. Other components, cover of broadleaves (except clover), amount of bare surface, and cover of microphytic crust, appeared not to be influential on the first PC. The eigenvalue of the second PC was always $<1$ and therefore was not adding to the explanation of variability [22].

These potential associations of cover with richness were further investigated by regression analyses for pitfall, sweepnetting, and combined data. The pairwise regressions of richness (dependent variable) on total plant cover and covers of native grasses, introduced annual grasses, clover species, and surface litter were tested for significance for each sampling period and two combinations of sampling periods (two examples are given in Figure 4). Significant, positive regressions were found for richness on native grass cover (eight occasions) and clover cover (5); see Table 5. Negative regressions of richness on surface litter cover (3) and cover of introduced grass (1) were also found. No association was found between richness and total cover. The significant associations with native grass occurred mainly in summer with pitfall richness and combined methods richness (Table 5). Clover cover had no association with pitfall richness but showed three associations with sweep-netting richness.

Correlations between all pairwise combinations of the four variables that had significant associations with invertebrate richness were used to distinguish between possible direct effects of variables on richness, as opposed to indirect effects due to secondary associations. Clover and surface litter covers had a significant negative correlation $(r=-0.974$; 


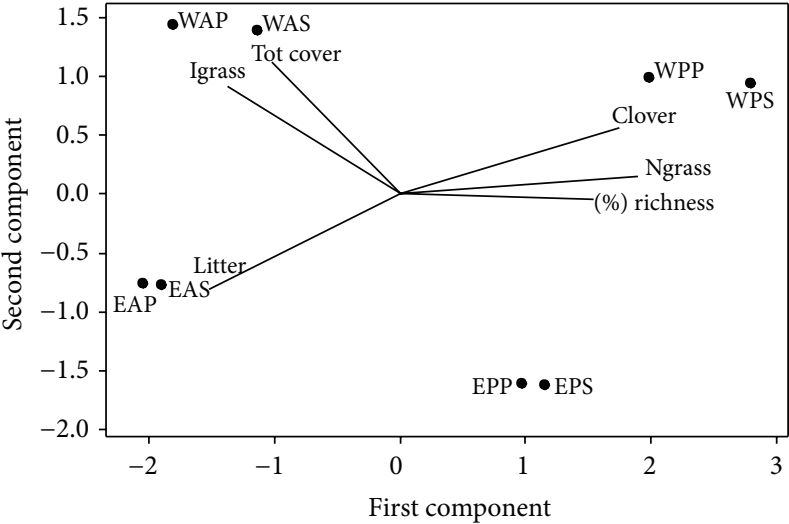

(a)

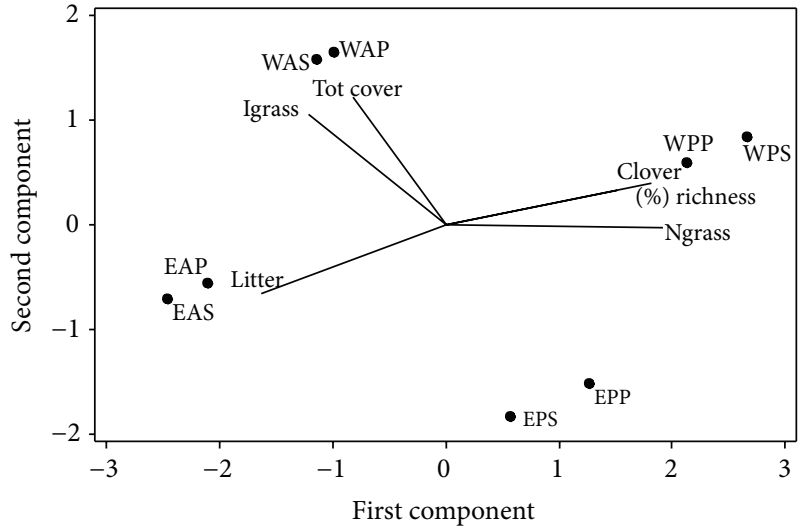

(b)

FIGURE 3: Examples of plots from exploratory principal components analyses of pitfall and sweep-netting morphospecies richness in (a) February 2007 and (b) the three surveys in 2007. Richness (\% richness) is the number of morphospecies, for a particular method and sampling area, as a percentage of total morphospecies for that method over all sampling areas. For each sampling area (EP, EA, etc.) percentage richness for pitfalls $(\mathrm{P})$ and sweep-netting $(\mathrm{S})$ is shown. Other variables are the covers of native grass (Ngrass), clovers, total plant cover (Tot cover), introduced grass (Igrass), and the cover of plant litter on the surface.

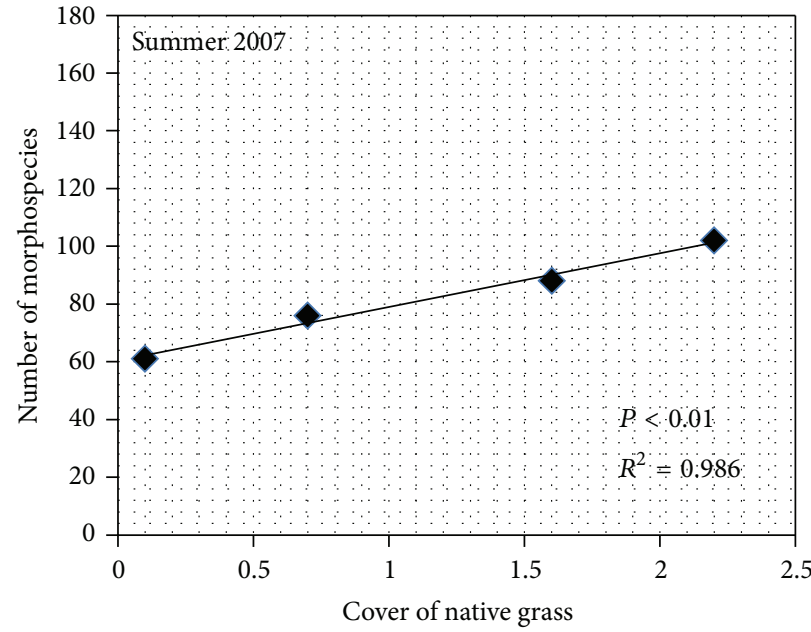

(a)

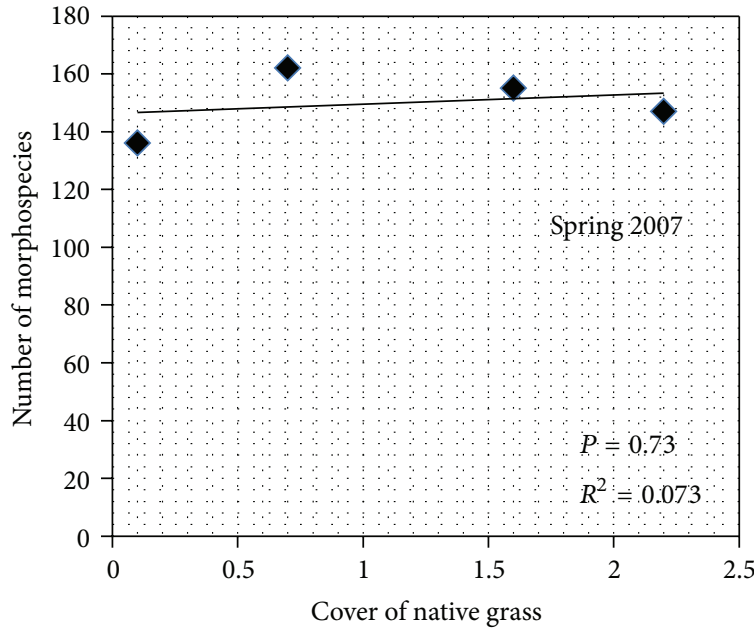

(b)

FIGURE 4: Examples of pairwise regressions of richness, from both capture methods, on cover of native grass. (a) February 2007 (regression ANOVA; $\left.F_{1,2}=134.6, P<0.01\right)$ and (b) October $2007\left(F_{1,2}=0.16, P=0.73\right)$.

$P<0.05)$. Clover and native grass covers were positively associated with borderline significance $(r=0.943 ; P \approx 0.05)$.

\section{Discussion}

4.1. Differences in Invertebrate Diversity between Sampling Areas. Comparisons of morphospecies richness between sampling areas indicate major differences between them. A numerical ranking based on richness gave the order WP > $\mathrm{EP}>\mathrm{WA} \geq \mathrm{EA}$, which was observed for three of the sampling periods and the two combinations of periods. Only in the October period was there a different order: $\mathrm{WA}>\mathrm{EP}>\mathrm{WP}>$ EA.
Statistical analysis of average species richness data confirmed the greater richness of $\mathrm{P}$ areas over A areas. Averages of the former were often significantly greater than those of the latter, but the reverse was never true. Furthermore, Fisher's $\alpha$ diversity data (based on pitfall captures only) mirrored the differences displayed for richness. EP or WP had the largest $\alpha$ and that of WA was usually greater than that of EA. In a number of instances these differences were statistically significant. In addition, the 289 morphospecies that were only captured in one of the sampling areas displayed a significant nonrandom distribution with EP and WP having more of these "single occurrences" than WA which, in turn, had more than EA. 
TABLE 5: Results of pairwise regressions of richness (dependent variable) on groundcover/surface variables. Only significant regressions ( $F$ test) are shown, as indicated by sign and significance level.

\begin{tabular}{|c|c|c|c|c|}
\hline \multirow{2}{*}{ Sampling period(s) } & \multirow{2}{*}{ Groundcover/surface variable } & \multicolumn{3}{|c|}{ Significant regression positive/negative } \\
\hline & & Pitfalls & Sweep-netting & Both methods \\
\hline \multirow{2}{*}{ February 2007} & Native grass cover & $+{ }^{*}$ & & $+{ }^{* *}$ \\
\hline & Clover cover & & & $+^{*}$ \\
\hline \multirow{4}{*}{ July 2007} & Native grass cover & & & $+^{*}$ \\
\hline & Clover cover & & $+^{* *}$ & \\
\hline & Introduced grass cover & $-{ }^{*}$ & & \\
\hline & Litter cover & & $-^{*}$ & \\
\hline \multirow{2}{*}{ October 2007} & Native grass cover & & $+^{*}$ & \\
\hline & Clover cover & & $+^{* *}$ & \\
\hline February 2008 & Native grass cover & $t^{*}$ & $t^{* *}$ & $+^{*}$ \\
\hline \multirow{2}{*}{2007 (3 surveys combined) } & Clover cover & & $+^{*}$ & \\
\hline & Litter cover & & $--^{* *}$ & \\
\hline \multirow{3}{*}{ February 2007 and 2008} & Native grass cover & & & $+^{*}$ \\
\hline & Clover cover & & & $+^{*}$ \\
\hline & Litter cover & & $--^{* *}$ & \\
\hline
\end{tabular}

It should be noted that differences in diversity appear to be based more on morphospecies numbers rather than differences in abundance, since there was no significant difference in the latter between sample areas averaged over sample periods.

4.2. Diversity Differences and Seasonal Changes. The spring sampling period had the highest richness and $\alpha$ diversity, whereas winter had the lowest of each measure and summer sampling periods were intermediate. Spring was also the period that showed the smallest relative differences in richness and $\alpha$ diversity between sampling areas, whereas they were greatest in the summer sampling periods. That is, differences in the typical rank order (WP $>$ EP $>$ WA $>$ EA) were most evident in summer.

It may be argued that the lower diversity in WA and EA in summer sampling periods is not of consequence because differences tend to disappear in the spring sampling period. However, when seasonal turnover of morphospecies is considered [5], the consequences of significantly lower diversity in summer are obvious. Of all morphospecies captured in the three periods in $2007,76 \%$ were captured in only one period, and only $15 \%$ were captured in both summer and spring. Thus, the suite of morphospecies present in summer is largely replaced in spring, and therefore a species "missing" in summer from a particular area is also likely to be "missing" in other seasons.

4.3. Associations between Invertebrate Diversity and the Groundcover/Surface. There seems little doubt that there are differences in invertebrate diversity between the four sampling areas. The four areas also have considerable differences from one another with respect to total vegetative cover, floristic composition, and, to a lesser extent, the nature of the surface. Are any of these differences associated with the differences in invertebrate diversity?

PCA and regression analyses revealed a negative association between litter cover and richness but positive associations for covers of native grass and clover with richness. Have any of these factors affected richness directly?

If the extent of litter cover was negatively affecting species richness directly, it is logical to suggest that this effect would be most evident in captures of surface-active invertebrates, that is, in pitfall captures. However, there were no significant regressions between litter cover and pitfall richness but three significant ones between litter cover and sweep-netting richness. This suggests a secondary association between these two factors via another unknown factor(s) rather than any direct effect of litter cover on richness.

If native grass cover has a direct effect on richness, such an effect could be expected to be greatest in summer and winter. The groundcover/surface survey was done only in spring, but floristic composition and plant cover are assumed to be very different in summer. In the Mediterranean-type summer of the survey site, perennial native grasses usually maintain some growth providing live plant material for invertebrates. Their tussocks and dried inflorescences may also provide shelter. In spring there are many other sources of plant material suggesting that native grass will have less influence. On the other hand, the clover species are introduced annuals with little, or no, presence in summer and likely to be represented only by seedlings or small plants in winter. Their maximum influence can be expected in spring when plants are large and flowering. They also have the notable advantage of high nitrogen content which may attract invertebrates in spring and may have some lingering influence as their litter decomposes in following seasons. However, the clovers have a spreading, prostrate habit which may limit their positive 
influence on sweep-netting captures, since they are below the physical level of the net.

If this reasoning is accepted and if both native grass cover and clover cover are having a direct influence on richness, regression of richness (dependent variable) on native grass cover should be greatest in summer and winter and least in spring, and the opposite should be true for similar regressions involving clover cover. Also, any direct effect in the latter case should be more obvious in pitfall captures than sweep-netting captures. The regressions for native grass cover and richness follow the suggested pattern and suggest a direct effect of native grass on richness. However, regressions for clover cover and richness do not follow the suggested, opposite pattern and also show positive associations in sweep-netting captures. This does not suggest a direct effect of clover on richness but rather a secondary association, possibly because of the positive correlation between native grass and clover covers. Of course, this does not prove a direct effect for native grass, but it does show a strong and logical association between native grass cover and invertebrate morphospecies richness.

\section{Conclusion}

With only four sampling areas and one survey site, any conclusions must be tentative. However, the results of summer sampling show greater morphospecies richness and/or diversity in areas with greater cover of native grasses. Statistical analyses show a strong positive association between cover of native grass and richness and there is a logical explanation for this association, which suggests a direct effect of native grass cover on invertebrate richness. If this direct effect exists, the loss of native grasses has serious implications not only for plant biodiversity but also for the invertebrates, which may be one of the largest components of biodiversity in these southern temperate grasslands.

\section{Conflict of Interests}

The author declares that there is no conflict of interests regarding the publication of this paper.

\section{Acknowledgments}

The author wishes to thank Annette Scanlon for her help in the field and assistance with laboratory work. The author is grateful for review of some statistical analyses by Ross Frick. Peter Allen provided critical comment on an earlier draft of this paper. The Native Grasses Resources Group of South Australia generously provided financial assistance to support this project.

\section{References}

[1] K. McDougall and J. B. Kirkpatrick, Conservation of Lowland Native Grasslands in South-Eastern Australia, World Wide Fund for Nature Australia, 1994.
[2] K. L. McDougall, T. J. Barlow, and M. L. Appleby, "Basalt plains, lake Omeo, Murray Valley Riverine Plains and the Wimmer," in Conservation of Lowland Native Grasslands in South-Eastern Australia, K. McDougall and J. B. Kirkpatrick, Eds., pp. 44-112, World Wide Fund for Nature Australia, 1994.

[3] M. K. Hyde, "South Australia," in Conservation of Lowland Native Grasslands in South-Eastern Australia, K. McDougall and J. B. Kirkpatrick, Eds., pp. 116-128, World Wide Fund for Nature, Morges, Switzerland, 1994.

[4] A. L. Yen, P. A. Horne, and A. J. Kobelt, "Invertebrates of the Victorian basalt plains grasslands," Australian Heritage Commission, 1995.

[5] R. E. Clay and P. G. Allen, "Invertebrates of grassland in the eastern Adelaide Hills: community composition and temporal changes," Transactions of The Royal Society of South Australia, vol. 138, no. 2, pp. 293-304, 2014.

[6] M. J. Samways, Insect Diversity Conservation, Cambridge University Press, Cambridge, UK, 2005.

[7] A. P. Schaffers, I. P. Raemakers, K. V. Sýkora, and C. J. F. Ter Braak, "Arthropod assemblages are best predicted by plant species composition," Ecology, vol. 89, no. 3, pp. 782-794, 2008.

[8] T. R. New, "How useful are ant assemblages for monitoring habitat disturbance on grasslands in south eastern Australia?" Journal of Insect Conservation, vol. 4, no. 3, pp. 153-159, 2000.

[9] I. G. Faithfull, Biodiversity impacts of Chilean needle grass Nassella neesiana on Australian indigenous grasslands [Ph.D. thesis], Victoria University, Melbourne, Australia, 2012.

[10] S. Torrusio, M. M. Cigliano, and M. L. de Wysiecki, "Grasshopper (Orthoptera: Acridoidea) and plant community relationships in the Argentine pampas," Journal of Biogeography, vol. 29, no. 2, pp. 221-229, 2002.

[11] R. Biedermann, R. Achtziger, H. Nickel, and A. J. A. Stewart, "Conservation of grassland leafhoppers: a brief review," Journal of Insect Conservation, vol. 9, no. 4, pp. 229-243, 2005.

[12] Biodiversity Conservation Alliance (BCA), Center for Biological Diversity, Center for Native Ecosystems et al., Petition to List the Dakota Skipper, 2003, http://www.xerces.org/wp-content/ uploads/2008/06/dakota_skipper_petition.pdf.

[13] M. F. Braby and M. Dunford, "Field observation on the ecology of the golden sun moth, Synemon plana Walker (Lepidoptera: Castniidae)," Austral Entomology, vol. 33, no. 2, pp. 103-110, 2006.

[14] BOM, "Australian Bureau of Meteorology," http://www.bom .gov.au/climate/data/.

[15] Environment and Water Resources, "Peppermint box (Eucalyptus odorata) grassy woodland of South Australia and irongrass natural temperate grassland of South Australia," EPBC Act Policy Statement 3.7: Nationally Threatened Species and Ecological Communities, Australian Government, Department of the Environment and Water Resources, 2007.

[16] P. J. M. Greenslade, "Sampling ants with pitfall traps: digging-in effects," Insectes Sociaux, vol. 20, no. 4, pp. 343-353, 1973.

[17] G. G. E. Scudder, Pifall trapping, (Environment Canada), 2006, http://www.eman-rese.ca.

[18] M. Abensperg-Traun and D. Steven, "The effects of pitfall trap diameter on ant species richness (Hymenoptera: Formicidae) and species composition of the catch in a semi-arid eucalypt woodland," Australian Journal of Ecology, vol. 20, no. 2, pp. 282$287,1995$.

[19] I. Oliver and A. J. Beattie, "Invertebrate morphospecies as surrogates for species: a case study," Conservation Biology, vol. 10, no. 1, pp. 99-109, 1996. 
[20] D. C. Montgomery, Design and Analysis of Experiments, Wiley, 4th edition, 1997.

[21] A. E. Magurran, Measuring Biological Diversity, Blackwell, London, UK, 2004.

[22] K. McGarigal, S. Cushman, and S. Stafford, Multivariate Statistics for Wildlife and Ecology Research, Springer, New York, NY, USA, 2000. 

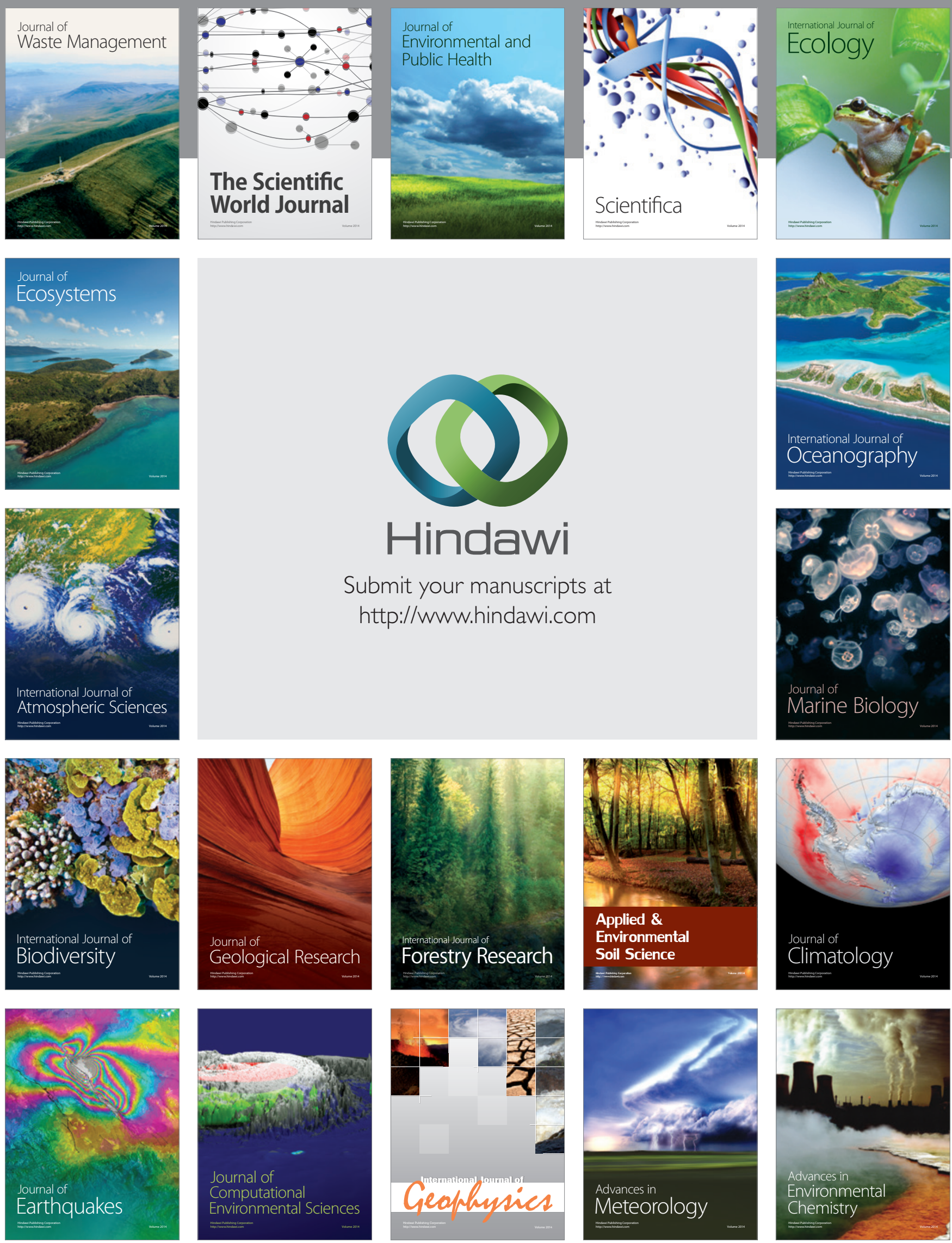